\title{
SENSEI ANGELA DE CASTRO GOMES UMA BREVE HOMENAGEM À PROFESSORA EMÉRITA DO CPDOC/FGV
}

Sensei Angela de Castro Gomes: a tribute to the Professor Emeritus of CPDOC/FGV

PAULO FONTES

http://dx.doi.org/10.1590/\$2178-14942016000200014

Paulo Fontes é professor da Escola de Ciências Sociais (CPDOC) da Fundação Getulio Vargas (FGV) e editor de Estudos Históricos (paulo.fontes@fgv.br) 


\author{
Senhor diretor do CPDOC/FGV, \\ Prezada Professora Emérita do CPDOC da FGV, Lucia Lippi Oliveira, \\ Prezada Professora Emérita do CPDOC da FGV, Angela de Castro Gomes, \\ Prezada colega Professora Luciana Heymann, \\ Prezado colega Professor Bernardo Buarque de Hollanda, \\ Prezado colega Professor João Marcelo Maia, \\ Senhoras e senhores desta distinta audiência, \\ Boa noite a todos e todas!
}

É uma enorme alegria ter a honra de estar presente neste evento e prestar esta breve e comovida homenagem à professora emérita Angela de Castro Gomes. Com sinceridade, sei que muitos aqui mereceriam muito mais do que eu o privilégio de estar neste púlpito hoje. Vários dos aqui presentes a conhecem há décadas e tiveram a satisfação de conviver por muito mais tempo do que eu com Angela, seja como alunos(as), como colegas de departamento, de pesquisas ou mesmo como amigos. Assim, agradeço de coração aos meus colegas da Congregação do CPDOC que - numa atitude de coragem e justiça - conferiram o título de professoras eméritas a Lucia Lippi e Angela de Castro Gomes e me concederam a honraria de representá-los nesta mesa.

Esta certamente não é uma tarefa fácil - o que torna o meu nervosismo neste momento plenamente justificável. Primeiro, porque falo depois da professora Luciana e do professor Bernardo, duas das pessoas mais elegantes que conheço, não apenas no trato e no comportamento, mas, como vocês acabaram de ouvir em duas belíssimas falas, também extremamente elegantes no manejo das palavras. Mas a tarefa é árdua principalmente porque é muito difícil dar conta de homenagear à altura uma intelectual pública da dimensão e envergadura de Angela de Castro Gomes, uma das maiores historiadoras do país e uma das almas que constituíram esta instituição no que ela tem de melhor e a tornou referência nacional e internacional: o rigor acadêmico, o compromisso público, o engajamento profundo com a pesquisa, com o ensino e com os debates sobre a democracia e a cidadania. 
A tarefa é difícil, mas profundamente necessária. Angela de Castro Gomes, vírgula, Professora Emérita do CPDOC da FGV. Difícil pensar em um aposto para Angela que fosse mais adequado e mais justo do que esse. Impossível e equivocado pensar o CPDOC sem Angela como sua professora emérita. Mas vamos por partes.

Primeiro, a professora. A conexão de Angela com o ensino é tão profundamente enraizada que "professora" parece ter sido incorporado ao seu próprio nome. "Professora Angela" é tão internalizado que provavelmente muitos de nós só concebem chamá-la desta forma. Não é para menos. Angela começou a lecionar em 1966, há exatos 50 anos. Normalista, dividia seu tempo entre as aulas que dava no curso primário do Grupo Escolar Casa de Samir, na zona rural de Niterói, com as aulas que recebia como aluna do curso noturno de História da Universidade Federal Fluminense. A intensa relação com o ensino era uma tradição da humilde família do norte do Estado do Rio. Neta de um professor autodidata, que chegou a diretor de Liceu, e filha de professora também normalista, Angela seguiria a mesma trilha e iria além...

Formada, e após um período na Europa escapando aos horrores da ditadura brasileira, iniciaria uma longa carreira como professora universitária, lecionando história contemporânea inicialmente na PUC-Rio. Dali, nos anos 80 e 90, marcaria época como um dos principais nomes da Universidade Federal Fluminense. Inicialmente no departamento de Ciências Sociais e logo em seguida no de História, ela rapidamente se tornaria uma das principais referências daquele departamento, fortalecendo uma graduação já consagrada e colaborando fundamentalmente para a construção de uma pós-graduação que se tornou amplamente reconhecida como uma das melhores do país. Mesmo aposentada na UFF no final dos anos 90, Angela como minha colega Luciana já ressaltou - foi uma das figuras centrais para o estabelecimento de uma área de ensino no CPDOC, tanto em nível de graduação quanto na pós-graduação. Mas, como sabemos, sua carreira de professora não parou por aí, e hoje o Departamento de História da UNIRIO tem o privilégio de tê-la como professora visitante sênior.

Ao longo desses anos foram dezenas de cursos lecionados para certamente milhares de alunos e alunas; 30 orientações de mestrado e 30 de doutorado concluídas; participação em mais de 200 bancas de mestrado, doutorado, titularidade, livre docência e concursos públicos. Os alunos e alunas por ela formados e orientados - muitos aqui presentes - compõem já diferentes gerações que têm construído parte importante do salto historiográfico que o país vivenciou nas últimas décadas.

São estatísticas para impressionar qualquer Plataforma Sucupira. Mas, para além dessa longa trajetória e desses números hiperbólicos, sabemos que é a imensa qualidade, o interesse e preocupação genuína pelo(a)s aluno(a)s e suas pesquisas, a solicitude, a generosidade, mas também o rigor, a cobrança, que caracterizam o estilo por ela mesmo denominado de 
"professora à moda antiga". 'Todos aqui devem ter uma história que denota algumas dessas características de Angela. Eu mesmo tenho a minha. Não tive a sorte de ser seu aluno, mas lembro bem do nosso primeiro contato - muito antes de eu sequer imaginar que um dia seria seu colega de instituição ou seria um dos responsáveis por lhe prestar esta homenagem hoje. Estávamos numa reunião da Anpocs em Caxambu, no final dos anos 90, e eu, aquela altura jovem doutorando da Unicamp, timidamente me aproximei de Angela, já uma consagrada historiadora, e após uma rápida conversa entreguei um disquete - sim, um disquete - com minha dissertação de mestrado. Num ato de ousadia, deixei também meu e-mail. Para minha enorme surpresa, alguns dias depois recebi uma mensagem dela com vários comentários perspicazes e observações de enorme valia sobre o meu trabalho.

Pois é essa rara mistura de generosidade, rigor e atenção que torna Angela a "professora Angela", a nossa professora Angela.

Segundo, emérita. Dona de uma carreira brilhante com amplo respeito no campo historiográfico e das ciências sociais em geral, Angela de Castro Gomes é uma das raras pesquisadoras em nossa área que é bolsista de Produtividade $1 \mathrm{~A}$ do CNPq e unanimemente reconhecida como uma das maiores historiadoras do país. Somente ela e Boris Fausto escreveram textos em duas das coleções consideradas as mais importantes de nossa historiografia (História geral da civilização brasileira, dirigida inicialmente por Sergio Buarque de Holanda e depois pelo próprio Fausto, e Historia da vida privada no Brasil). Angela tem cerca de 50 livros publicados, de autoria própria ou por ela organizados, e mais de 150 artigos e capítulos publicados em coletâneas e em vários dos mais prestigiosos periódicos nacionais e internacionais. Se os números mais uma vez impressionam, a qualidade, abrangência e impacto dessa produção impressionam ainda mais. Vários desses livros e artigos tornaram-se obras de referência em nossas ciências sociais. Em breve me deterei com um pouco mais de detalhe em A invenção do trabalhismo, mas antes gostaria de lembrar como Angela tem navegado com maestria por várias mares intelectuais.

Burguesia e trabalho, ${ }^{2}$ seu primeiro livro, de finais dos anos 1970, já era uma análise pioneira - em que também desafiava antigas dicotomias e periodizações consagradas - sobre o papel ativo do empresariado na construção da lógica e estrutura corporativa do Estado brasileiro. Ao lado de Alzira Abreu, Maria Celina D’Araújo, Aspásia Camargo, Helena Bomeny, Dulce Pandolfi, Marieta de Moraes Ferreira, Mônica Kornis e Lucia Lippi entre outras colegas de CPDOC, Angela estabeleceu um paradigma para os estudos da história política e intelectual da República brasileira, redefinindo a abordagem de temas como o regionalismo, o corporativismo e o autoritarismo, entre outros. ${ }^{3}$ A chamada Era Vargas foi um termo em grande medida definido por essa produção. 0 apreço pelo trabalho coletivo e a feliz articulação entre a 
organização e a reflexão sobre fontes primárias são um legado dessa geração. A construção de um amplo acervo de arquivos pessoais e de história oral, áreas em que o CPDOC foi pioneiro, proporcionou que Angela nos oferecesse trabalhos de enorme envergadura sobre figuras-chave da República. Evaristo de Moraes, Arnaldo Sussekind, San Thiago Dantas, Gustavo Capanema, Oliveira Viana, João Goulart e o próprio Getulio Vargas tiveram aspectos cruciais de suas trajetórias políticas e intelectuais analisados por ela. ${ }^{4}$

0 mergulho sistemático nessas fontes também proporcionou riquíssimas reflexões metodológicas e teóricas. Além das discussões sobre história oral, onde, ao lado de colegas como Marieta de Moraes Ferreira e Verena Alberti, Angela foi uma das figuras proeminentes, seus trabalhos e análises sobre narrativas autobiográficas, correspondências pessoais, diários, as chamadas "escritas de si", tornaram-se clássicos e já têm influenciado gerações de estudantes e historiadores. ${ }^{5}$ Tais reflexões certamente impulsionaram Angela para uma análise do próprio ofício do historiador, da história do campo historiográfico e, indo além, do próprio mundo intelectual - em particular o carioca. Assim, há todo um rico investimento de Angela na historicidade da própria história do Brasil, com estudos interessantíssimos sobre o IHGB, sobre a historiografia nacional anterior aos anos 30, sobre Viriato Correa, as relações entre a história e o rádio, entre outros. ${ }^{6}$ Aqui cabe também destacar como sua experiência de professora influenciou igualmente sua agenda de pesquisa, tendo como resultado toda uma análise sistemática consubstanciada em livros e artigos sobre o próprio campo do ensino da história. ${ }^{7}$

Mas Angela, ignorando rótulos e caixinhas acadêmicas, também é uma grande historiadora social. Suas análises sobre as conexões entre os mundos do trabalho, a cultura política e o Estado no Brasil resultam até hoje em reflexões inovadoras e instigantes sobre temas que vão da Justiça do Trabalho, passando pelos estudos migratórios até o estudo do trabalho análogo à escravidão contemporâneo. ${ }^{8}$

De acordo com o Dicionários Aurélio e Houaiss, emérito é aquele ou aquela que tem prestado longos e excepcionais serviços, aquele ou aquela muito versado ou versada, com grande experiência e prestígio. Ou seja: Angela de Castro Gomes.

Terceiro, do CPDOC. Em uma entrevista concedida no início dos anos 2000, Angela disse: "para mim o CPDOC foi capital. Sou o que sou porque fui trabalhar no CPDOC em 1976". . Eu diria que o inverso também é verdadeiro: "O CPDOC é o que é porque teve Angela de Castro Gomes entre os seus quadros." Luciana já discorreu com muito mais competência do que eu seria capaz sobre a importância de Angela e Lucia na história da CPDOC. Uma incrível trajetória, cabe lembrar novamente, de fortes mulheres intelectuais comandando uma instituição de excelência em plena ditadura militar e redemocratização, remando contra a maré dominante do sexismo e do descaso com a memória e a história nacional. 
Angela, como já foi destacado, é parte fundamental dessa história. Mas vou me deter brevemente naquela que considero sua obra mais cepdoquiana, ao mesmo tempo sua obra mais importante e que em grande medida sintetiza muitas das suas análises, perspectivas e opções teóricas e metodológicas: $A$ invenção do trabalhismo. ${ }^{10}$

A invenção do trabalhismo foi a tese de doutoramento em ciência política de Angela no antigo IUPERJ, atual IESP, em 1987 (aliás, um pequeno parêntese, as conexões históricas entre o IUPERJ e o CPDOC - tradição que persiste até os dias de hoje - são um capítulo bem interessante a ser explorado na história intelectual brasileira). Publicado em livro no ano seguinte, o trabalho é, em minha opinião, ao lado de A tecelagem dos conflitos de classe na Cidade das Chaminés, de Jose Sérgio Leite Lopes, e de Trabalho, lar e botequim, de Sidney Chalhoub, uma das obras do final dos anos 80 que pautariam boa parte da agenda historiográfica na década seguinte, em particular no campo da história social. ${ }^{11}$

São muitas as razões que tornam $A$ invenção uma grande obra cepdoquiana. Trabalho de historiadora, fermentado com as discussões da ciência política e temperado com diálogos da sociologia e da antropologia (como na apreciação, que se tornaria clássica - e também polêmica - das relações entre trabalhadores e Vargas a partir das análises de Marcel Mauss sobre a "dádiva"), o livro tem uma forte perspectiva interdisciplinar, marca registrada do CPDOC.

Obviamente, um livro como aquele só poderia ser fruto da imersão de Angela nas fontes do CPDOC. Estão lá os documentos dos acervos de Vargas, Salgado Filho, Alexandre Marcondes Filho, Agamenon Magalhães, Filinto Muller, os depoimentos de dezenas de figuras públicas coletados pelo programa de história oral do CPDOC, mas também os relatórios, jornais e revistas (com destaque para a seminal Cultura Política). Mas não se tratava apenas do trabalho de uma pesquisadora talentosa tirando proveito de um arquivo excepcional. Tratava-se de alguém que ajudou a organizar esse mesmo arquivo e, ao fazê-lo, pôde dar um salto em sua reflexão teórica e metodológica.

Evidentemente, $A$ invenção é uma obra cepdoquiana em sua agenda de debates. Claro, a "Era Vargas"! E a era Vargas naquilo que ela teria de mais inovador e perene. Sua relação com o mundo - simbólico e material - dos trabalhadores e trabalhadoras. Neste sentido, Angela estava em diálogo direto não apenas com suas colegas no CPDOC, mas também, insisto neste ponto, com seus mestres do IUPERJ. Em A invenção, há uma conversa explicita com seu orientador Wanderely Guilherme dos Santos e sua concepção de "cidadania regulada", mas há também conversas com Luiz Werneck Vianna e o entendimento dos limites do liberalismo brasileiro e da força do pensamento autoritário. E, claro, a discussão sobre o corporativismo, tema de seu orientador de mestrado, Renato Boschi, está evidentemente presente. ${ }^{12}$ 
Mas A invenção consegue a proeza de colocar todos esses complexos temas e conceitos em uma narrativa histórica sofisticada e empiricamente sustentada. E o faz rompendo tradicionais fronteiras do campo historiográfico, articulando a história do pensamento social com a história política e, principalmente, com a história social. A análise dos discursos dos trabalhadores e sua complexa relação com o Estado e suas ressignificações sem dúvida é um dos pontos altos do livro. Neste sentido, $A$ invenção inova mais uma vez, ao incorporar em uma obra originalmente pensada como de história política, uma perspectiva de clara inspiração na obra de E. P. Thompson, naquele momento ainda relativamente pouco conhecida no Brasil. Desta forma, o livro deu uma importante contribuição para o alargamento da própria agenda de pesquisas do CPDOC, até aquele momento muito confinada a uma concepção razoavelmente restritiva de elite políticas.

Se, como lembra a própria Angela, a reação dos historiadores ao livro demorou um pouco, ${ }^{13}$ é possível identificar, já a partir dos anos 90, uma série de discussões motivadas por suas páginas. A mais famosa é, obviamente, a crítica avassaladora ao conceito de populismo em sua matriz weffortiana. Desde então muita pesquisa já foi feita e muitos aspectos da formulação sobre o trabalhismo como contraponto ao populismo já foram criticados e matizados. Mas não há dúvida de que depois da Invenção os marcos do debate nunca mais foram os mesmos. Um outro grande achado do livro diz respeito à sua periodização. Em particular, o marco de 1942 como uma inflexão fundamental na política getulista fomentou toda uma nova discussão sobre as características do Estado Novo e o peso dessa inflexão no processo de redemocratização e criação da República de 1946. A sensibilidade da autora para os aspectos simbólicos, como a criação de um calendário festivo pelo regime varguista, e para o peso da lei na cultura política dos trabalhadores foi outra inovação que vem inspirando reflexões e pesquisas desde então. A análise dos discursos radiofônicos do ministro Alexandre Marcondes Filho foi inédita e inspiradora. Mesmo a (a meu juízo) correta crítica da ausência do discurso e ação operária, especialmente na segunda parte livro, o que teria levado a uma análise por demais "a partir de cima" em vários momentos, só pode ser feita à luz das possibilidades de análise justamente abertas pela própria obra. Ademais, como sabemos, o valor de um livro deve ser medido não apenas pelo que ele diz, mas também pelo debate que ele provoca. $\mathrm{E}$ neste sentido, eu não hesitaria em dizer que $A$ invenção do trabalhismo colocou Angela de Castro Gomes em um exclusivo rol dos intérpretes do Brasil.

Nestes dias tristes e perigosos em que vivemos, um tempo da "não delicadeza", a agenda intelectual e política que motivou a redação de $A$ invenção do trabalhismo continua viva e atual. Escrito em um momento de esperança com a construção da democracia e de uma cidadania que avançasse no combate às seculares desigualdades sociais e buscasse uma 
maior justiça social, ele continua uma fonte de inspiração para aqueles que acreditam que o conhecimento histórico e o debate intelectual são armas fundamentais na busca desses objetivos.

Para terminar, gostaria de lembrar um outro grande historiador: o britânico Eric Hobsbawm. Em seu livro Sobre História, ele nos explica o real significado do termo japonês sensei, qual seja: "um mestre intelectual para quem se deve algo que não pode ser retribuído". ${ }^{14}$

Em meu nome, da Congregação do CPDOC e, acredito, em nome de todos aqui presentes, eu gostaria de encerrar dizendo à nossa professora emérita:

Muito obrigado, SenseiAngela de Castro Gomes!!!

\section{NOTAS}

1 Conferir a entrevista de Angela de Castro Gomes in MORAES, José Geraldo Vinci e REGO, José Marcio (orgs.). Conversas com historiadores brasileiros. São Paulo: Editora 34, 2002, p. 302.

2 Burguesia e trabalho: política e legislação social no Brasil (1917-1937). Rio de Janeiro: Campus, 1979. Uma reedição do livro foi publicada pelo Editora 7 Letras em 2014.

3 Conferir, entre outros, GOMES, Angela de Castro et alii. Regionalismo e centralização política (partidos e Constituinte nos anos trinta). Rio de Janeiro: Nova Fronteira, 1980; OLIVEIRA, Lucia Lippi; VELLOSO, Mônica Pimenta; GOMES, Angela Maria de Castro. Estado Novo: ideologia e poder. Rio de Janeiro: Zahar, 1982; GOMES, Angela de Castro e D'ARAÚJO, Maria Celina. Getulismo e trabalhismo: tensões e dimensões do PTB. São Paulo: Ática, 1988; GOMES, Angela de Castro. Vargas e a crise dos anos 50. Rio de Janeiro: Relume Dumará, 1994; e GOMES, Angela de Castro. Minas e fundamentos do Brasil moderno. Belo Horizonte: UFMG, 2005.

4 Conferir, entre outros, GOMES, Angela de Castro et alii. Diário: Getúlio Vargas. Rio de Janeiro: FGV/Siciliano, 1995; GOMES, Angela de Castro. Capanema: o ministro e seu ministério. Rio de Janeiro/Bragança Paulista: Ed. FGVIEd.USF, 2000; GOMES, Angela de Castro (org.). Em família: a correspondência de Oliveira Lima e Gilberto Freyre. Campinas: Mercado de Letras, 2005. v. 1.; GOMES, Angela de Castro e FERREIRA, Jorge. Jango: as múltiplas faces. Rio de Janeiro: Editora FGV, 2007; GOMES, Angela de Castro, PESSANHA, Elina e MOREL, Regina. Sem medo da utopia: Evaristo de Moraes, arquiteto da sociologia e do Direito do Trabalho no Brasil. São Paulo: Editora LTr, 2007.

5 Ver GOMES, Angela de Castro (org.). Escrita de si, escrita da história. Rio de Janeiro: Editora FGV, 2004; GOMES, Angela de Castro e SCHMIDT, Benito (orgs.). Memórias e narrativas (auto)biográficas. Rio de Janeiro/ Porto Alegre: Ed. FGV/Ed. UFRGS, 2009.

6 Conferir, da autora, História e historiadores: a política cultural do Estado Novo. Rio de Janeiro: FGV, 1996; Essa gente do Rio. Modernismo e nacionalismo. Rio de Janeiro: Ed. FGV, 1999; Personagens e imagens de uma cidade. Rio de Janeiro: Mauad/FAPERJ, 2001; A República, a história e o IHGB. Belo Horizonte: Fino Traço, 2012, e A biblioteca de Viriato Corrêa: incursões sobre a leitura e a escrita de um intelectual brasileiro,in DUTRA, Eliana de Freitas (org.), O Brasil em dois tempos: história, pensamento social e tempo presente. Belo Horizonte: Autêntica, 2013. 
7 Ver, entre outros, História de chinelo: 0 ensino de História através do rádio no Brasil dos anos 1950, in ROCHA, Helenice; MAGALHÃES, Marcelo e GONTIJO, Rebeca (orgs.). O ensino de História em questão: cultura histórica, usos do passado. Rio de Janeiro: Ed. FGV, 2015.

8 Conferir, da autora, Histórias de imigrantes e de imigração no Rio de Janeiro. Rio de Janeiro: 7 Letras, 2000; Histórias de família: entre a Itália e o Brasil. Niterói: Muiraquitã, 1999; Memórias da imigração espanhola em Niterói. Niterói: UFF, 2006 (em coautoria com Ana Maria Mauad); O Tribunal Regional do Trabalho da $1^{a}$ Região e a Justiça do Trabalho no Brasil. Rio de Janeiro: TRT, 2006; Memória da Justiça do Trabalho: trajetória de juízes. Porto Alegre: Ed. Porto Alegre, 2010; e A Justiça do Trabalho e sua história. Campinas: Editora Unicamp, 2013 (co-organizado com Fernando Teixeira da Silva).

9 Conferir MORAES, José Geraldo Vinci e REGO, José Marcio (orgs.). Conversas com historiadores brasileiros. São Paulo: Editora 34, 2002, p. 297.

10 A invenção do trabalhismo. São Paulo: Vértice, 1988. Uma segunda edição foi publicada pela Editora Relume Dumará em 1994 e uma terceira, pela Editora da FGV em 1995. A Editora da FGV tem publicado novas edições desde então.

11 Ver LEITE LOPES, José Sérgio. A tecelagem dos conflitos de classe na Cidade das Chaminés. São Paulo: Marco Zero e Universidade de Brasília em co-edição com MCT/CNPq, 1988, e CHALHOUB, Sidney. Trabalho, lar e botequim: o cotidiano dos trabalhadores no Rio de Janeiro da Belle Époque. São Paulo: Brasiliense, 1986.

12 SANTOS, Wanderley Guilherme dos. Cidadania e Justiça: a política social na ordem brasileira. Rio de Janeiro: Campos, 1979; VIANNA, Luiz Werneck. Liberalismo e sindicato no Brasil. Rio de Janeiro: Paz e Terra, 1976; e BOSCHI, Renato (org.). Corporativismo e desigualdade: a construção do espaço público no Brasil. São Paulo: Vértice, 1991.

13 Conferir MORAES, José Geraldo Vinci e REGO, José Marcio (orgs.). Conversas com historiadores brasileiros. São Paulo: Editora 34, 2002, p. 296.

14 Conferir HOBSBAWM, Eric. Sobre História. São Paulo: Cia. das Letras, 1997, p. 9. 